\title{
Assessing spectral similarities between rainfed and irrigated croplands in a humid environment for irrigated land mapping
}

\section{S.A.M. Shamal and Keith Weatherhead}

\begin{abstract}
Deriving accurate spatial assessments of the distribution of irrigated crops has become more important in recent years for water resource planning, particularly where irrigation water resources are constrained. However, this is easier in arid climates than in humid areas such as eastern England. The challenges in using alternative vegetation indices derived from remote sensing to discriminate between irrigated and rainfed crops in a humid climate are described, focusing on potato (Solanum tuberosum L.), the most important irrigated crop in England. Three techniques were evaluated: (a) temporal profile comparisons using the Normalized Difference Vegetation Index (NDVI); (b) cluster analysis combining the NDVI and the Normalized Difference Water Index (NDWI); and (c) identifying differences in chlorophyll content using green and near infrared bands. However, the study confirmed that the spectral signatures of irrigated and rainfed potato in England during a typical summer are very similar, presumably due to frequent rainfall events which reduce differences in water stress and chlorophyll content. The implications for using remote sensing to estimate irrigated areas in humid climates are discussed.
\end{abstract}

Keywords: irrigated area estimation; potato; England; NDVI; NDWI

S.A.M. Shamal (corresponding author) is with the Agriculture and Horticulture Development Board - HGCA, Stoneleigh Park, Warwick CV8 2TL, UK. E-mail: shamal.mohammed@hgca.ahdb.org.uk. Keith Weatherhead is with Cranfield University, Bedford MK43 OAL, UK.

Remote sensing data have been widely used in the last three decades to identify and map land cover and land use types. They provide a relatively cheap and quick method to obtain agricultural statistics. Remote sensing techniques have proved their ability to identify irrigated areas in many parts of the world. There are examples from the USA (Wardlow et al, 2007), Greece (Alexandridis et al, 2008), Portugal (Grant et al, 2007), India (Biggs et al, 2006; Thenkabail et al, 2005), Iran (Akbari et al, 2006), Thailand (Kamthonkiat et al, 2005), Italy (Baruffi et al, 2005), Turkey (Ozdogan et al, 2003), Kazakhstan (El-Magd and Tanton, 2003) and Spain (Beltran and Belmonte, 2001). However, most of these studies were conducted under agroclimatic conditions where rainfall is low or negligible during the growing season. The lack of water for rainfed crops in such locations has a significant impact on their spectral properties. In contrast, in a humid climate, even rainfed crops receive water from intermittent summer rainfall, and their spectral properties are less affected. Mapping supplemental irrigated crops in humid or temperate climates using remote sensing techniques therefore requires a great deal of care and is not as straightforward as in arid or semi-arid climates (Droogers, 2002).

The total area irrigated in the UK reported by the Global Irrigation Area Map (GIAM) provides an example of the potential inaccuracy from estimating irrigated areas 
by using remote sensing in such climates. The International Water Management Institute (IWMI) produced the GIAM in 1999 by using remote sensing techniques and multi-temporal time series analyses of the Normalized Difference Vegetation Index (NDVI). Thenkabail et al (2009) estimated the UK irrigated area to be 970,733 ha, but this is about seven times greater than that given in official government statistics and survey data, which typically report around 150,000 ha (Knox et al, 2009). This significant difference in area estimation raises an important question regarding the accuracy of remote sensing techniques in mapping irrigated areas in all temperate or humid climates (Thenkabail et al, 2012). The objective of this study, therefore, was to evaluate the issues around using various alternative spectral vegetation indices and analytic approaches to identify the differences between irrigated and rainfed potato fields and to determine which method or combination of methods might provide the most accurate approach for irrigated area estimation.

\section{Materials and methods}

The study attempted to differentiate between irrigated and rainfed potatoes using three approaches. First, the temporal NDVI profiles were compared using MODIS and Landsat data, using NDVI as an indicator for the greenness profile of potato crops during the growing season. Second, the NDVI and Normalized Difference Water Index (NDWI) indices were used in an attempt to cluster irrigated and rainfed potatoes, using NDWI as an indicator for vegetation water content. Finally, the Green Index (GI) was added as an indicator of chlorophyll content. Ground truth data were obtained from the Potato Council (PCL) for 2003. This is a levy-funded organization that represents the interests of the potato industry, which collects detailed records of rainfed and irrigated potato areas for all its registered growers each year; the PCL data hence provide a valuable temporal geo-referenced dataset relating to cropped areas at the field scale.

\section{Study area}

In England, potatoes are among the most important irrigated crops in terms of production and value to the rural economy (Leathes et al, 2008). Potatoes represented over $40 \%$ of the total irrigated area and $56 \%$ of the total volume of irrigation water abstracted in England (Daccache et al, 2011). In 2008, 27\% of total cropped potatoes in the UK were located in eastern England, where soil and agroclimatic conditions for potato production are most suitable. However, this part of England suffers regular water shortages, with competition for water between public supplies, agriculture and the environment (Knox et al, 2010). The study area covered four sub-catchments where potato production is concentrated: namely, Grimsby and Ancholme, Louth, Welland and Witham (Figure 1).

\section{Temporal NDVI analysis}

Remote sensing vegetation indices provide a very useful tool for monitoring vegetation. There is a general agreement that the NDVI is the most important vegetation index to map, monitor and assess vegetation cover (Zhang et al, 2003; DeFries et al, 1998; Reed et al, 1994). NDVI is

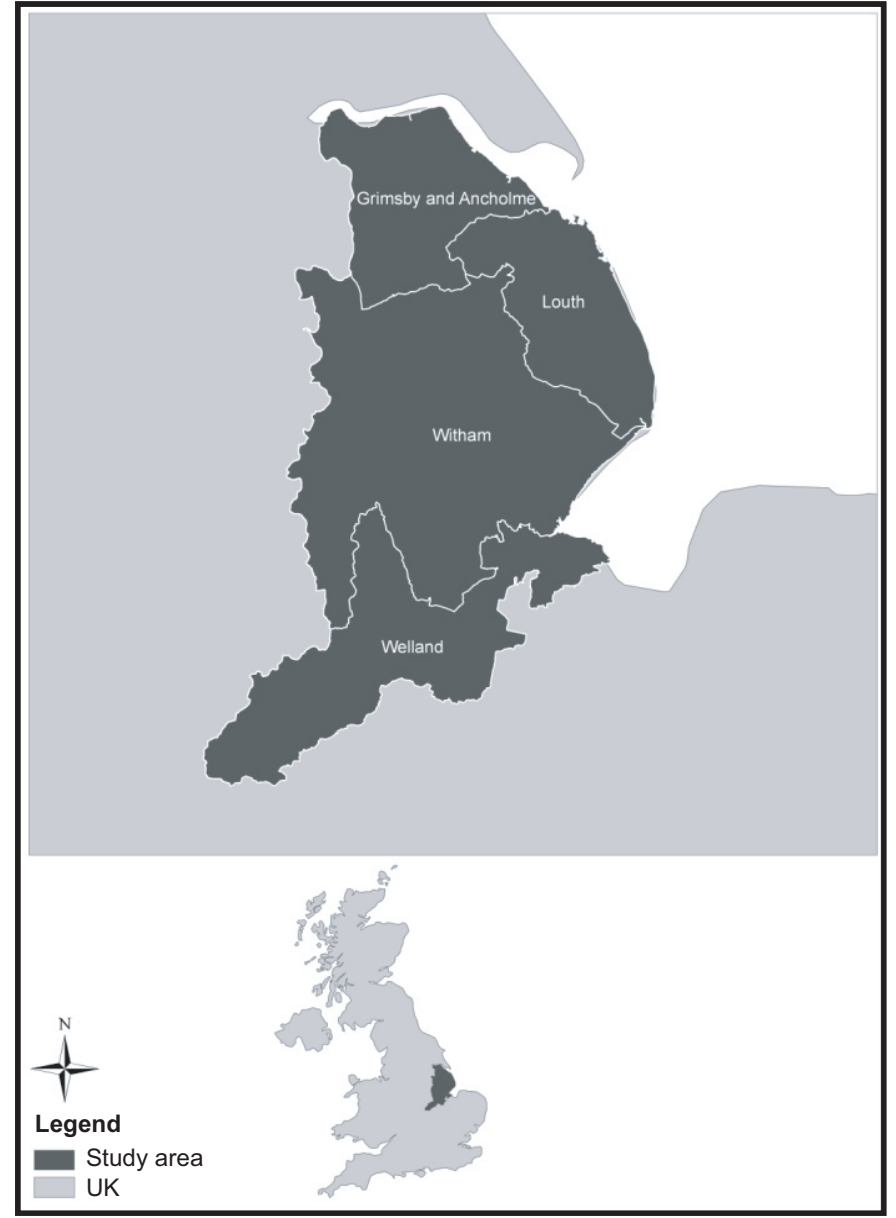

Figure 1. Location of the case study catchments in eastern England.

defined as the ratio between the reflectance of red $(R)$ and near infrared (NIR) bands in the electromagnetic spectrum:

$$
\text { NDVI }=\frac{\rho N I R-\rho R}{\rho N I R+\rho R}
$$

Ideally, the NDVI profile of an irrigated crop shows a higher value than that of a rainfed crop, reflecting that the canopy should be relatively greener due to the greater amount of available water.

(a) Using MODIS NDVI. Moderate Resolution Imaging Spectroradiometer (MODIS) was first used to obtain time series NDVI for the potatoes cropped in the case study catchments. This dataset has often been used in irrigated area mapping (Thenkabail et al, 2009; Beltran and Belmonte, 2001; Biggs et al, 2006; Ozdogan et al, 2003). A four-month time series of a 16-day NDVI composite of MODIS with a spatial resolution of $250 \mathrm{~m}$ was created, covering the growing season from the end of April to the end of August 2003. The composite image provides a near cloud-free image showing the maximum greenness over each 16-day period, which helps to reduce the cloud cover problem experienced on particular days. Nine MODIS images were downloaded from the Earth Observing 
System Data Gateway; these images cover the 2003 growing season (23 April to 29 August 2003) for the case study catchments. All images were stacked into a mega NDVI file to simplify the creation of temporal profiles for irrigated and rainfed potato field samples. The NDVI values for 1,083 irrigated potato fields and 902 rainfed potato field samples were determined. The field data were imported into a geographical information system (GIS) as a point layer and overlaid on to the mega NDVI file. The NDVI of the pixel containing each potato sample point had to be used as the NDVI of the potato field; this can be a potential problem due to the low spatial resolution of MODIS imagery $(250 \mathrm{~m})$ and the relatively small size of potato fields (typically 5 to $20 \mathrm{ha}$ ) in England.

(b) Using Landsat NDVI. The Landsat Thematic Mapper (TM) imagery was also used to compare the NDVI profiles of irrigated and rainfed potato fields. The Landsat imagery was used because it provides information relating to NDVI at a higher spatial resolution $(30 \mathrm{~m})$ than MODIS $(250 \mathrm{~m})$. It also provides the NDVI for potato fields on the day of acquisition, unlike the MODIS composite. Three Landsat scenes (path: 202; row: 23) were used to calculate NDVI. Images were acquired on 13 July, 30 August and 15 September 2003. The red and NIR bands were used to calculate NDVI for each scene. The data were downloaded from http://glovis.usgs.gov/.

However, a limitation of the Landsat imagery was found to be the cloud cover. Of the three images during the 2003 growing season, only the July one had no cloud cover; the August scene had 28\% and the September scene had $29.5 \%$ cloud cover across the four catchments in the study area. When the images were combined to create a time series profile, the proportions of cloud cover increased to $72.5 \%$ of the total study area. The potato fields located in the areas covered by cloud were removed from the subsequent analysis. As a result, only 170 irrigated and 172 rainfed potato fields were used to create the Landsat NDVI temporal profile.

\section{NDVI-NDWI analysis}

Whilst the NDVI provides information on the rate of photosynthesis and chlorophyll content, the NDWI can be used as an indicator of vegetation canopies' water content (Gao, 1996). The NDWI has been widely used to study vegetation water content (for example, Chen et al, 2005;
Cheng et al, 2006; Jackson et al, 2004; Zarco-Tejada et al, 2003) and for irrigated area mapping (Alexandridis et al, 2008). The NDWI is calculated as the ratio between near infrared (NIR) and mid-infrared (MIR) reflectance (Goa, 1996).

$$
\text { NDWI }=\frac{\rho N I R-\rho M I R}{\rho N I R+\rho M I R}
$$

During the summer months, rainfed potatoes are likely to experience higher water deficits than irrigated potatoes due to inadequate rainwater supply. In theory, irrigated crops are greener and have a higher moisture content than rainfed crops. The relationship between NDVI and NDWI might thus be used to split the rainfed and irrigated crops into two distinct clusters (Figure 2a). Hence, the values for NDVI and NDWI were calculated using the Landsat imagery acquired on 13 July 2003. The two indices were then plotted in order to determine the separability boundary between the clusters of irrigated and rainfed potato.

\section{The Green Index analysis}

A study by Gitelson et al (2003) suggested that the green band of spectral regions was more sensitive to chlorophyll content than the blue and red bands. Therefore the green band may best show the differences of light absorption by chlorophyll between irrigated and rainfed potatoes. The hypothesis is that there would be higher absorption of the green band (less reflection) and higher reflection of the NIR band from irrigated potatoes than from rainfed potatoes (Figure 2b) because of less moisture stress in irrigated potatoes than in rainfed potatoes.

Using the green band and NIR band together has been reported to be better than using NDVI to detect irrigated crops when the chlorophyll content and moisture stress of rainfed crops are similar to those of the irrigated crops (Ozdogan and Gutman, 2008). The ratio between these two bands can be expressed as the Green Index (GI):

$$
\mathrm{GI}=\mathrm{NIR} / \mathrm{G}
$$

The values of green and near infrared reflectance in the Landsat image taken on 13 July 2003 were therefore determined for 342 potato sites identified from the PCL survey data. The point data were plotted to help visualize the separability and determine the clusters of irrigated and rainfed potatoes.

(b)

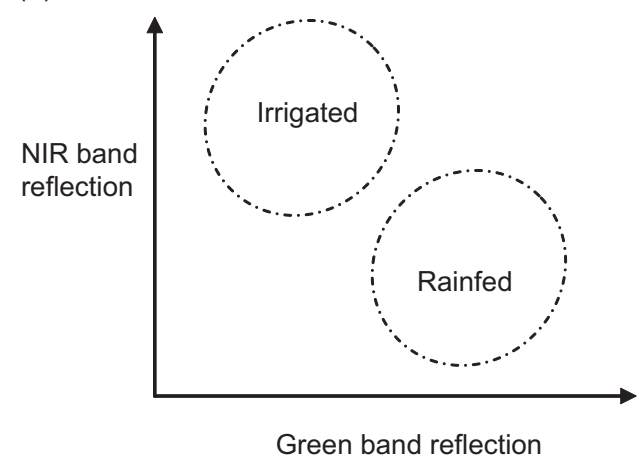

Figure 2. Idealized clusters for irrigated and rainfed crops based on (a) the NDVI-NDWI relationship and (b) the NIR and green band reflections. 


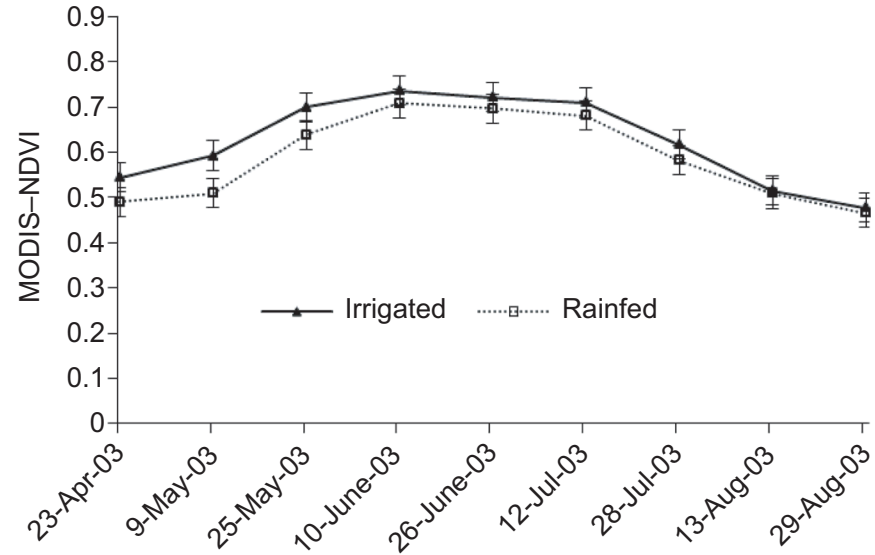

Figure 3. Temporal NDVI analysis of irrigated and rainfed potatoes in the case study catchments for the 2003 growing season.

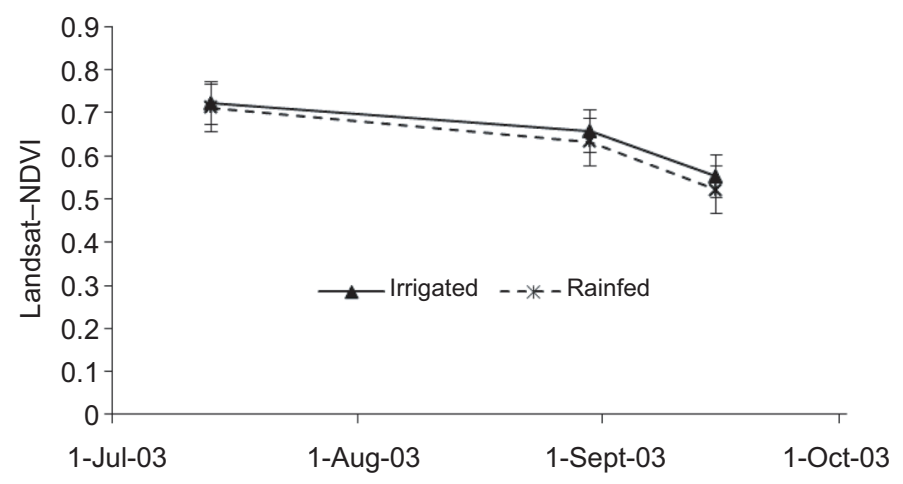

Figure 4. Time series NDVI comparison between irrigated and rainfed potatoes based on the average value of five fields each in the case study catchments in the 2003 growing season.

Note: Error bars show variability in NDVI values.

\section{Results and discussion}

\section{Temporal NDVI}

The results from the NDVI temporal analysis using the MODIS dataset (Figure 3) show that the mean values of NDVI for the irrigated fields were not significantly different from those for the rainfed fields, as two sample t-tests $(p=0.002)$ confirmed, and the differences in NDVI in the nine images were not sufficient to identify a threshold to classify the potato areas into irrigated and rainfed classes. The higher spatial resolution of the Landsat dataset did not improve the NDVI separability between the irrigated and rainfed potato crop types (Figure 4). These results confirm that rainfed potatoes have a very similar NDVI signal to potatoes that receive supplemental irrigation in England.

\section{NDVI-NDWI cluster}

The results from the NDVI-NDWI analysis (Figure 5) showed a high confusion in reflection between the irrigated and rainfed potatoes in relation to their chlorophyll activity and water content. All the irrigated and rainfed potato fields were located in the region where the NDVI ranged between 0.80 and 0.65 and the NDWI ranged

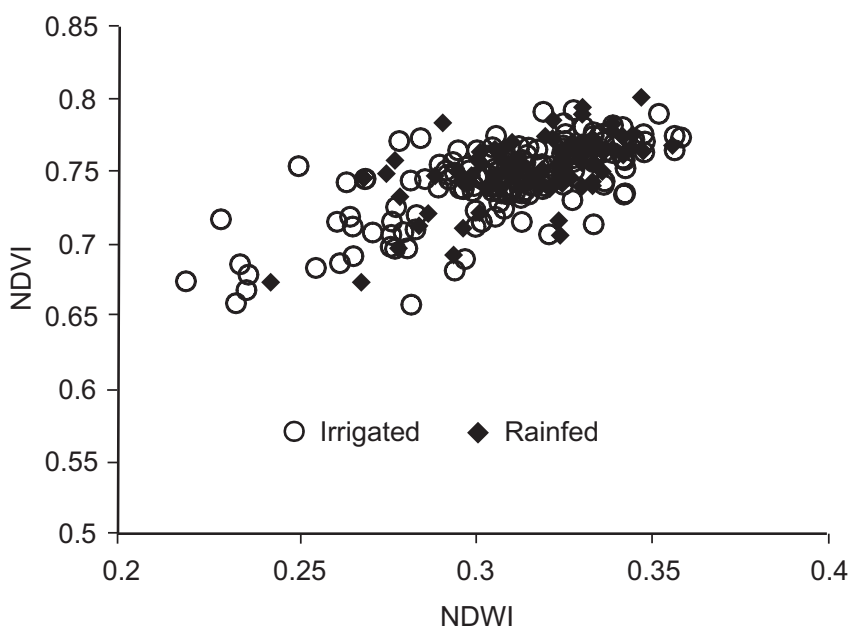

Figure 5. NDVI-NDWI relationship for irrigated and rainfed potatoes in study catchments, 13 July 2003.

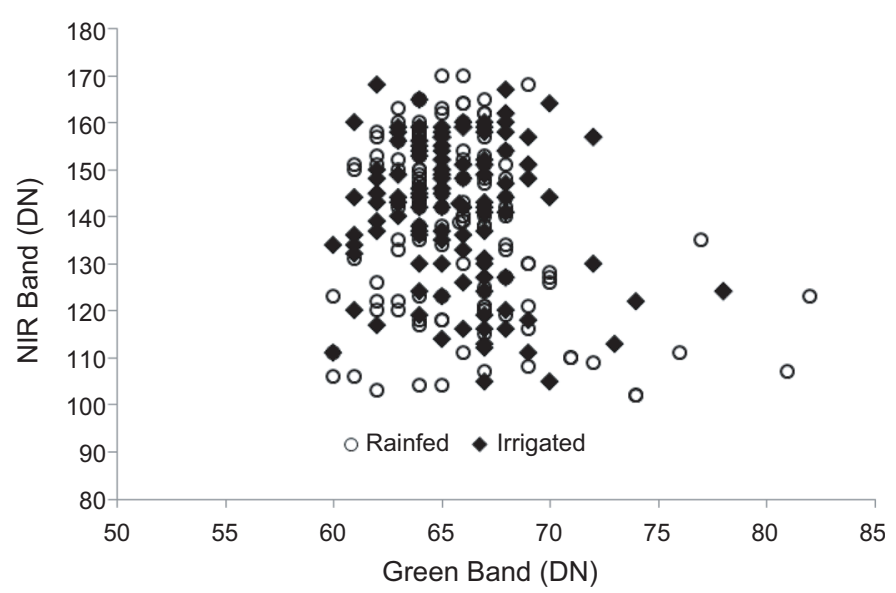

Figure 6. Irrigated and rainfed potato clusters based on green and NIR band reflections for the catchments in the study region in 2003.

between 0.25 and 0.37. Also, there was no significant difference in the mean NDVI and mean NDWI. The points were distributed in a single very narrow cluster with high overlap between irrigated and rainfed samples. This result was further evidence of the similarity in spectral reflections of potatoes grown under temperate climate conditions.

\section{Chlorophyll content}

Figure 6 shows that the irrigated and rainfed potatoes also had very similar reflected values in the green and NIR bands. The mean reflectance was about 70 digital numbers (DNs) in the green band and about 130 DNs in the NIR for both irrigated and rainfed potato samples. In theory, rainfed potato samples were expected to concentrate where the values of NIR were lower and the green band values were higher, because they absorb less electromagnetic radiation in the green band compared with irrigated crops. The relationship between green and NIR bands again did not provide any clear evidence of any clusters between irrigated and rainfed potatoes. 


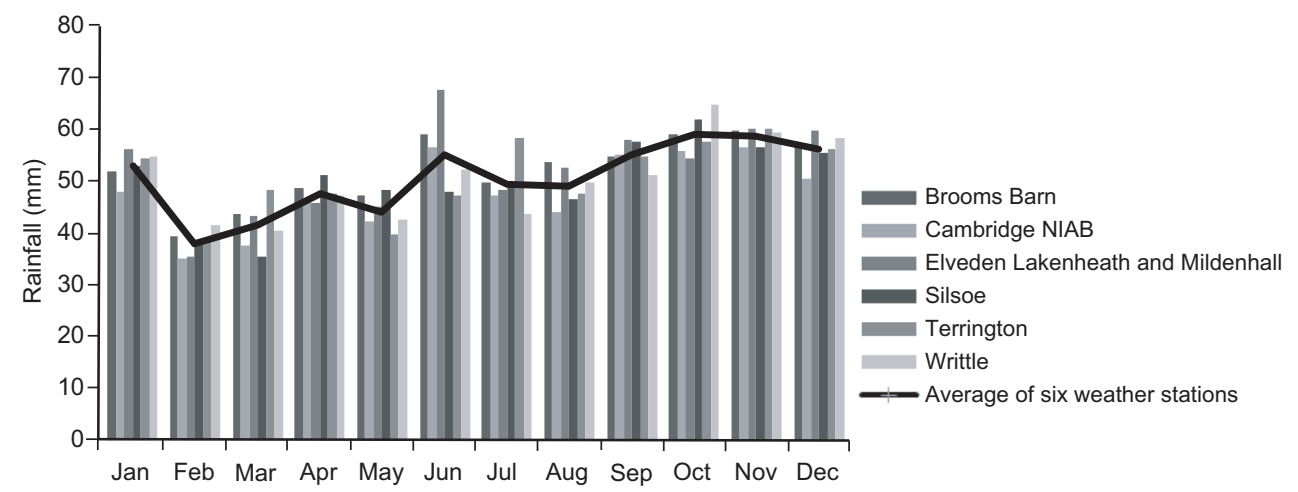

Figure 7. Average monthly rainfall (1983-2003) in six weather stations in the study area.

\section{Discussion}

In the study area, there are frequent summer rainfall events, and average summer rainfall is about a quarter of the total annual rainfall, based on six weather stations in the catchments (Figure 7). The supplementary irrigation of potatoes is as much for maximizing quality and controlling disease as for maximizing yield. In most soils there are sufficient available soil moisture reserves provided by the summer rainfall to limit the degree of crop water stress in most years. Indeed, unirrigated potatoes would probably not be grown on sites where frequent severe water stress did occur.

It is perhaps not surprising therefore that the rainfed potatoes did not show any significant differences in NDVI. The differences may be more obvious in a very dry year when summer rainfall is less significant, and on less water-retentive soils. It may therefore be better to restrict the analysis to dry years (when there is also less cloud cover), and possibly to combine the remote sensing datasets with spatial information datasets on soil type.

\section{Summary}

The study found that irrigated and rainfed potato crop signatures measured using standard remote sensing techniques were remarkably similar and, using the datasets and indices investigated, remote sensing data alone were unable to distinguish between irrigated and rainfed potato fields in eastern England. Summer rainfall reduces the differences in chlorophyll content and moisture content between irrigated and rainfed crops, and gives the crops similar spectral properties. Classifications using indices derived or calibrated in arid areas to map irrigated land in humid areas may therefore lead to large overestimation (or underestimation) errors due to this high spectral similarity between the rainfed and irrigated crops. Wherever possible, the measurements need to be subjected to ground-truthing against local data on which crops are irrigated and not irrigated.

There is therefore a need to develop a more accurate approach to deal with supplemental irrigation mapping in temperate or humid climates. The next research step should be to assess and compare the accuracy of irrigated area estimations using the Global Irrigated Area Map (GIAM) under different climatic conditions: namely, arid, semi-arid and humid regions, and to investigate developing a specific method for irrigated area estimation in humid and temperate climates using combinations of thermal emissivity, vegetation indices and other datasets, combined with local calibration and error estimation based on ground truth.

\section{Acknowledgments}

The authors acknowledge the support and provision of field data and statistics from the UK AHDB Potato Council levy board.

\section{References}

Akbari, M., Mamanpoush, A.R., Gieske, A., Miranzadeh, M., Torabi, M., and Salemi, H.R. (2006), 'Crop and land cover classification in Iran using Landsat 7 imagery', International Journal of Remote Sensing, Vol 27, No 19, pp 4117-4135.

Alexandridis, T.K., Zalidis, G.C., and Silleos, N.G. (2008), 'Mapping irrigated area in Mediterranean basins using low cost satellite Earth Observation', Computers and Electronics in Agriculture, Vol 64, No 2, pp 93-103.

Baruffi, F., Cappelletto, M., Bisaglia, M., and Zandonella, A. (2005), 'Crop classification and crop water need estimation of Piave river basin by using MIVIS, Landsat-TM/ETM+ and ground-climatological data', Proceedings of SPIE - The International Society for Optical Engineering, 5976 (1Q), SPIE, Bellingham, WA.

Beltran, C.M., and Belmonte, A.C. (2001), 'Irrigated crop area estimation using Landsat TM imagery in La Mancha, Spain', Photogrammetric Engineering and Remote Sensing, Vol 67, No 10, pp 1177-1184.

Biggs, T.W., Thenkabail, P.S., Gumma, M.K., Scott, C.A., Parthasaradhi, G.R., and Turral, H.N. (2006), 'Irrigated area mapping in heterogeneous landscapes with MODIS time series, ground truth and census data, Krishna Basin, India', International Journal of Remote Sensing, Vol 27, No 19, pp 4245-4266.

Chen, D., Huang, J., and Jackson, T.J. (2005), 'Vegetation water content estimation for corn and soybeans using spectral indices derived from MODIS near- and short-wave infrared bands', Remote Sensing of Environment, Vol 98, Nos 2-3, pp 225-236.

Cheng, Y., Zarco-Tejada, P.J., Riaño, D., Rueda, C.A., and Ustin, S.L. (2006), 'Estimating vegetation water content with hyperspectral data for different canopy scenarios: relationships between AVIRIS and MODIS indexes', Remote Sensing of Environment, Vol 105, No 4, pp 354-366.

Daccache, A., Weatherhead, E.K., Stalham, M.A., and Knox, J.W. (2011), 'Impacts of climate change on irrigated potato production in a humid climate', Agricultural and Forest Meteorology, Vol 151, pp 1641-1653. 
De Fries, R.S., Hansen, M., Townshend, J.R.G., and Sohlberg, R. (1998), 'Global land cover classifications at $8 \mathrm{~km}$ spatial resolution: the use of training data derived from Landsat imagery in decision tree classifiers', International Journal of Remote Sensing, Vol 19, No 16, pp 3141-3168.

Droogers, P. (2002), Global Irrigated Area Mapping: Overview and Recommendations, Working Paper 36, International Water Management Institute, Colombo, Sri Lanka.

El-Magd, I.A., and Tanton, T.W. (2003), 'Improvements in land use mapping for irrigated agriculture from satellite sensor data using a multi-stage maximum likelihood classification', International Journal of Remote Sensing, Vol 24, No 21, pp 41974206.

Gao, B. (1996), ‘NDWI - a normalized difference water index for remote sensing of vegetation liquid water from space', Remote Sensing of Environment, Vol 58, No 3, pp 257-266.

Gitelson, A.A., Gritz, Y., and Merzlyak, M.N. (2003), 'Relationships between leaf chlorophyll content and spectral reflectance and algorithms for non-destructive chlorophyll assessment in higher plant leaves', Journal of Plant Physiology, Vol 160, No 3, pp 271-282.

Grant, O.M., Tronina, L., Jones, H.G., and Chaves, M.M. (2007), 'Exploring thermal imaging variables for the detection of stress responses in grapevine under different irrigation regimes', Journal of Experimental Botany, Vol 58, No 4, pp 815-825.

Jackson, T.J., Chen, D., Cosh, M., Li, F., Anderson, M., Walthall, C., Doriaswamy, P., and Hunt, E.R. (2004), 'Vegetation water content mapping using Landsat data derived normalized difference water index for corn and soybeans', Remote Sensing of Environment, Vol 92, No 4, pp 475-482.

Kamthonkiat, D., Honda, K., Turral, H., Tripathi, N.K., and Wuwongse, V. (2005), 'Discrimination of irrigated and rainfed rice in a tropical agricultural system using SPOT VEGETATION NDVI and rainfall data', International Journal of Remote Sensing, Vol 26, No 12, pp 2527-2547.

Knox, J.W., Rodriguez-Diaz, J.A., Weatherhead, E.K., and Kay, M.G. (2010), 'Development of a water strategy for horticulture in England and Wales', Journal of Horticultural Science and Biotechnology, Vol 85, No 2, pp 89-93.

Knox, J.W., Shamal, S.A.M., Weatherhead, E.K., and RodriguezDiaz, J.A. (2009), 'The challenges of mapping irrigated areas in a temperate climate: experiences from England', in Thenkabail, P.S., Turral, H., Biradar, C., and Lyon, J.G., eds, Remote Sensing of Global Croplands for Food Security, CRC Press, Boca Raton, FL, pp 237-250.
Leathes, W., Knox, J.W., Kay, M.G., Trawick, P., and RodriguezDiaz, J.A. (2008), 'Developing UK farmers' institutional capacity to defend their water rights and effectively manage limited water resources', Irrigation and Drainage, Vol 57, No 3, pp 322-331.

Ozdogan, M., and Gutman, G. (2008), 'A new methodology to map irrigated areas using multi-temporal MODIS and ancillary data: an application example in the continental US', Remote Sensing of Environment, Vol 112, No 9, pp 3520-3537.

Ozdogan, M., Woodcock, C.E., and Salvucci, G.D. (2003), 'Monitoring changes in irrigated lands in southeastern Turkey with remote sensing', International Geoscience and Remote Sensing Symposium No 3, Melbourne, pp 1570-1572.

Reed, B.C., Brown, J.F., Vanderzee, D., Loveland, T.R., Merchant, J.W., and Ohlen, D.O. (1994), 'Measuring phenological variability from satellite imagery', Journal of Vegetation Science, Vol 5, No 5, pp 703-714.

Thenkabail, P.S., Biradar, C.M., Noojipady, P., Dheeravath, V., Li, Y., Velpuri, M., Gumma, M., Gangalakunta, O.R.P., Turral, H., Cai, X., Vithanage, J., Schull, M.A., and Dutta, R. (2009), 'Global irrigated area map (GIAM), derived from remote sensing, for the end of the last millennium', International Journal of Remote Sensing, Vol 30, No 14, pp 3679-3733.

Thenkabail, P.S, Knox, J.W., Ozdogan, M., Gumma, M.K., Congalton, R.G., Wu, Z.T., Milesi, C., Finkral, A., Marshall, M., Mariotto, I., You, S.C., Giri, C., and Nagler, P. (2012), 'Assessing future risks to agricultural productivity, water resources and food security: how can remote sensing help?' Photogrammetric Engineering and Remote Sensing, Vol 78, No 8, pp 773-782.

Thenkabail, P.S., Schull, M., and Turral, H. (2005), 'Ganges and Indus river basin land use/land cover (LULC) and irrigated area mapping using continuous streams of MODIS data', Remote Sensing of Environment, Vol 95, No 3, pp 317-341.

Wardlow, B.D., Egbert, S.L., and Kastens, J.H. (2007), 'Analysis of time-series MODIS $250 \mathrm{~m}$ vegetation index data for crop classification in the U.S. Central Great Plains', Remote Sensing of Environment, Vol 108, No 3, pp 290-310.

Zarco-Tejada, P.J., Rueda, C.A., and Ustin, S.L. (2003), ‘Water content estimation in vegetation with MODIS reflectance data and model inversion methods', Remote Sensing of Environment, Vol 85, No 1, pp 109-124.

Zhang, X., Friedl, M.A., Schaaf, C.B., Strahler, A.H., Hodges, J.C.F., Gao, F., Reed, B.C., and Huete, A. (2003), 'Monitoring vegetation phenology using MODIS', Remote Sensing of Environment, Vol 84, No 3, pp 471-475. 